\title{
Insusceptibility to disinfectants in bacteria from animals, food and humans - is there a link to antimicrobial resistance?
}

\author{
Karin Schwaiger ${ }^{1+}$, Katrin S. Harms ${ }^{1}$, Meike Bischoff ${ }^{1}$, Petra Preikschat ${ }^{2}$, Gabriele Mölle ${ }^{2}$, \\ Ilse Bauer-Unkauf ${ }^{2}$, Solveig Lindorfer ${ }^{1}$, Sandra Thalhammer ${ }^{1}$, Johann Bauer ${ }^{1}$ and \\ Christina S. Hölzel ${ }^{1 * t}$
}

${ }^{1}$ Animal Hygiene, Wissenschaftszentrum Weihenstephan für Ernährung, Landnutzung und Umwelt, Technische Universität München, Freising, Germany

${ }^{2}$ Bavarian Health and Food Safety Authority (LGL), Erlangen, Germany

\section{Edited by:}

Mark Montforts, National Institute for Public Health and the

Environment, Netherlands

\section{Reviewed by:}

Atte Von Wright, University of

Eastern Finland, Finland

Rob De Jonge, National Institute for

Public Health and the Environment,

Netherlands

Sara V. Lundstrom, University of

Gothenburg, Sweden

\section{*Correspondence:}

Christina S. Hölzel, Animal Hygiene, Wissenschaftszentrum

Weihenstephan für Ernährung,

Landnutzung und Umwelt,

Technische Universität München,

Weihenstephaner Berg 3, 85354

Freising, Germany

e-mail:christina.hoelzel@

wzw.tum.de

${ }^{\dagger}$ Present address:

Karin Schwaiger, Food Safety,

Department of Veterinary Science,

Faculty of Veterinary Medicine,

LMU München, Oberschleißheim,

Germany;

Christina S. Hölzel, Hygiene and

Technology of Milk, Department of

Veterinary Science, Faculty of

Veterinary Medicine, LMU

München, Oberschleißheim,

Germany
Enterococcus faecalis $(n=834)$ and Enterococcus faecium $(n=135)$ from blood and feces of hospitalized humans, from feces of outpatients and livestock and from food were screened for their susceptibility to a quaternary ammonium compound (didecyldimethylammoniumchloride, DDAC) and to 28 antibiotics by micro-/macrodilution. The maximum DDAC-MIC in our field study was $3.5 \mathrm{mg} / \mathrm{l}$, but after adaptation in the laboratory, MIC values of $21.9 \mathrm{mg} / \mathrm{l}$ were observed. Strains for which DDAC had MICs > $1.4 \mathrm{mg} / \mathrm{l}$ ("non-wildtype," in total: 46 of 969 isolates $/ 4.7 \%$ ) were most often found in milk and dairy products $(14.6 \%)$, while their prevalence in livestock was generally low (0-4\%). Of human isolates, $2.9-6.8 \%$ had a "non-wildtype" phenotype. An association between reduced susceptibility to DDAC, high-level-aminoglycoside resistance and aminopenicillin resistance was seen in E. faecium $(p<0.05)$. No indications for a common source of non-wildtype strains were found by RAPD-PCR; however, several non-wildtype $E$. faecalis shared the same variant of the emeA-gene. In addition, bacteria $(n=42)$ of different genera were isolated from formic acid based boot bath disinfectant $(20 \mathrm{ml}$ of $55 \%$ formic acid/l). The MICs of this disinfectant exceeded the wildtype MICs up to 20-fold (staphylococci), but were still one to three orders of magnitude below the used concentration of the disinfectant (i. e., 1.1\% formic acid). In conclusion, the bacterial susceptibility to disinfectants still seems to be high. Thus, the proper use of disinfectants in livestock surroundings along with a good hygiene praxis should still be highly encouraged. Hints to a link between antibiotic resistance and reduced susceptibility for disinfectants-as seen for E. faecium—should be substantiated in further studies and might be an additional reason to confine the use of antibiotics.

Keywords: disinfectant, biocide, antiseptic, antimicrobial resistance, QAC, formic acid, enterococci, aminoglycoside

\section{INTRODUCTION}

Prevention of zoonoses-including the spread of antimicrobial resistant bacteria-is mainly a question of how to reduce the prevalence of contagious microorganisms. Whenever actions are taken to reduce the spread of bacteria in livestock, effective disinfection is crucial.

Antimicrobial resistance is basically increasing whenever resistant bacteria are selected by antimicrobial use (Bronzwaer et al., 2002; Lipsitch and Samore, 2002; Livermore, 2005). A certain antibiotic agent might directly select for resistance directed against itself, might indirectly (cross-)select for cross-resistance to chemically related agents and/or might (co-)select for coresistance to unrelated substances (Shah, 2005), the latter based e.g., on co-transfer of resistance genes due to genetic linkage on mobile elements. Besides co-selection posed by antibiotic agents, diverse other co-selectors are discussed, e.g., heavy metal ions (Berg et al., 2005; Baker-Austin et al., 2006; Hölzel et al., 2012), pesticides (Bordas et al., 1997), or disinfectants (Levy, 2000). For several bacterial species, including methicillin resistant Staphylococcus aureus, a link between resistance against antibiotics and reduced susceptibility for disinfectants has been described in the past (Heir et al., 1999; Bjorland et al., 2001, 2005; Sidhu et al., 2002a). At the same time, other studies did not find clear indications for co-resistance against antibiotics and disinfectants (Suller and Russell, 2000; Loughlin et al., 2002). Enterococci-apart from VRE-have rarely been investigated for this correlation up to now, despite the fact that enterococci are emerging - meanwhile maybe better called: 
“emerged"—nosocomial pathogens (Tailor et al., 1993; Willems and van Schaik, 2009) with a high recombination potential (Aarestrup et al., 2002; Leavis et al., 2006; Palmer and Gilmore, 2010; Schwaiger et al., 2011, 2012).

Acquired insusceptibility to disinfectants can be conferred by newly acquired genes (like qac-genes, Poole, 2002) or by mutations, e.g., of intrinsic multidrug transporters (like nor A, emeA, Kaatz et al., 1993; Ng et al., 1994; Jonas et al., 2001) or of target structures (e.g., cell membranes), although the latter is described to be a rare event with biocides (Poole, 2002). To slightly complicate the situation, the mere presence of qac-genes seems to correlate only weekly with phenotypic insusceptibility; instead, induced overexpression of qac-genes might explain a reduced phenotypic susceptibility in a more satisfactory way (Cervinkova et al., 2012).

Bacteria that are contemporaneously resistant to antibiotics and disinfectants are a worrying scenario. According to their telling name, multidrug transporters have more than one substrate (which might be chemically unrelated to each other). In this way, multidrug transporters seem to be predisposed to confer multiresistance. However, in most cases the unspecific efflux provided by multidrug transporters leads to not more than slightly elevated MIC-values below clinical antimicrobial resistance (Lee et al., 2003). Multiresistance might also result from a combination of newly acquired genes. Such genes can be physically linked on common genetic elements like plasmids or transposons and might spread to other strains, species or genera, independent from their original carriersas shown for qac-genes and bla-genes (Bjorland et al., 2005). Moreover, links between antibiotic resistance and tolerance to disinfectants might also be caused by the clonal spread of co-resistant strains-irrespective of whether this co-resistance is encoded within the intrinsic or within the variable gene pool. This might be the reason why most evidence for coresistance to antibiotics and disinfectants is found in MRSAstrains, which are known to spread often in clonal complexes (Oliveira et al., 2002). Although antibiotic resistance in enterococci is thought to spread mainly via the horizontal spread of resistance genes (Willems et al., 2011), successful clonal lineages have also been identified (Nallapareddy et al., 2005; Leavis et al., 2006).

In case of co- or cross-resistance to disinfectants, any discussion should be very carefully balanced, since adequate disinfection is crucial for any hygienic concept (Cozad and Jones, 2003), in hospitals as well as on farms or in the food producing industry. Russell (2000) emphasizes that the term cross-resistance is problematic for the situation seen up to now with antibiotics and disinfectants, since all studies which report on this phenomenon use disinfectant concentrations far below practically applied concentrations. This means that, up to now, we are talking about "microbiological" or "epidemiological" resistance to disinfectants. Such strains differ from the wildtype by elevated MIC-values, but still have MIC-values below "clinically" or "in praxi" used (breakpoint) concentrations.

The present study aimed to investigate a representative number of Enterococcus faecalis $(n=824)$ and Enterococcus faecium ( $n=130)$ from diverse sources (hospital/food industry/farm animals) for their susceptibility to a disinfectant (didecydimethylammoniumchlorid, DDAC) and 22 antibiotic agents. The distribution of strains with DDAC-MICs $>$ or $<1.4 \mathrm{mg} / \mathrm{l}$ within antibiotic resistant and susceptible strains was assessed. In case of elevated DDAC-MIC-values strains were investigated for clonal relationship using amplicon-typing (RAPD-PCR). In several isolates, the emeA-genotype, coding for a multidrug efflux transporter, was further investigated by melting curve analysis and sequencing.

The higher the initial MIC of strains the more rapidly they might be adapted to rising concentrations of disinfectants, as shown by Sidhu et al. (2002b). Therefore, we performed additionally an exploratory adaptation test with the DSM 2570 reference strain and three strains with DDAC_MICs $>1.4 \mathrm{mg} / \mathrm{l}$.

To have a first glance on real life conditions, different bacterial species were additionally isolated from the disinfectant fluid of boot baths and tested for their MIC-values for DDAC, formic acid and antibiotics.

\section{MATERIALS AND METHODS COLLECTION AND IDENTIFICATION OF STRAINS}

All Enterococcus strains $(n=954)$ were collected and identified in the frame of the second Bavarian antimicrobial resistance monitoring project (BAVMAP II, Bischoff et al., 2012) by speciesspecific PCR as previously described (Bischoff et al., 2012). Isolates from disinfectant boot bath were taken in three different ways:

(i) By direct culturing from the disinfectant fluid.

(ii) By means of a sterile swab which was subsequently introduced in TS-broth ( $30 \mathrm{~g}$ cold filterable tryptone soya broth per 11 of distilled water) supplemented with a specific inactivation medium for organic acids. The inactivation medium was recommended by the German Veterinary Medical Society (DVG, 2008) and was added to the disinfectant with final concentrations of $3 \%$ tween $80,3 \%$ saponin, $0.3 \%$ lecithin, $0.3 \%$ sodium thiosulphate, $0.1 \%$ histidin, $0.01 \mathrm{~mol} / \mathrm{l}$ disodium hydrogenphosphate.

(iii) By means of a sterile swab as described above, but without inactivation medium.

Swabs and disinfectant fluid were streaked on nutrient agar with 7\% sheep blood, on Gassner agar, CATC-agar, and Schaedler agar; plates were incubated aerobically or anaerobically (Schaedler Agar) for $48 \mathrm{~h}$. Single colonies were picked, subcultured, and preliminary identified by colony morphology, Gram staining, oxidase-, catalase-, and indolereaction, as well as growth and characteristics on selective agar (Fluorocult agar, VWR, Darmstadt, Germany; CATC agar, VWR; Baird Parker agar, Otto Nordwald, Hamburg, Germany). Results were confirmed by commercial biochemical test sets (API ${ }^{\circledR} / \mathrm{ID}-32$, bioMérieux, Nürtingen, Germany; BBL ${ }^{\mathrm{TM}}$ Crystal $^{\mathrm{TM}}$ Enteric/Nonfermenter ID Kit, BD, Heidelberg, Germany) and species-specific PCR (enterococci, Bischoff et al., 2012). 


\section{SUSCEPTIBILITY TESTS}

Disinfectants

Microdilution. The susceptibility of all 969 enterococcal strains to didecyldimethylammoniumchloride (DDAC) (Tradename Sokrena, Bode Chemie, Hamburg, Germany) was assessed in a microdilution procedure as previously described (Bischoff et al., 2012). In brief, TS-Broth (30 g cold filterable Tryptone Soya Broth per 11 distilled water) containing $1 \times 10^{8}-1 \times 10^{9} \mathrm{cfu}$ of the test strain per $\mathrm{ml}$ was diluted 1:100 in water of standardized hardness (WSH, consisting of $0.89 \mathrm{~g}$ waterfree $\mathrm{NaCl}_{2}$ and $0.5 \mathrm{~g} \mathrm{MgCl}_{2} \times 7 \mathrm{H}_{2} \mathrm{O}$ per 3.3:1 of distilled water), resulting in bacterial concentrations of $1 \times 10^{6}-1 \times 10^{7} \mathrm{cfu}$ per $\mathrm{ml}$. Then, $100 \mu \mathrm{l}$ of a double concentrated DDAC-WSH solution was manually placed into each well of a 96 well microtiter plate. Thirteen $\mathrm{ml}$ of TS-broth was inoculated with $226 \mu \mathrm{l}$ of the 1:100 diluted bacterial suspension, and $100 \mu \mathrm{l}$ of the resulting suspension was pipetted into each (DDAC-WSH filled) well of the microtiter plate by a semiautomatic dispenser (Micronaut Sprint, Genzyme-Virotech). Microtiter plates were covered with transparent plastic films and incubated at $37^{\circ} \mathrm{C}$ for $72 \mathrm{~h}$, as specified in the instructions of the German Veterinary Medical Society (DVG, 2008); the microbial growth was visually investigated after 24 and $72 \mathrm{~h}$.

Macrodilution. MIC-values $>1.4 \mathrm{mg} / \mathrm{l}$ in the microdilution test were confirmed in the DVG-reference macrodilution test. Bacterial suspensions were prepared as for the microdilution test; $100 \mu \mathrm{l}$ of these suspensions were added to $4.9 \mathrm{ml}$ of TS-broth + DDAC (DDAC-concentrations of $0.14-1400 \mathrm{mg} / \mathrm{l}$, corresponding to a ready-to-use solution with $0.0002-2 \%=0.002-20 \mathrm{ml}$ disinfectant stock solution per liter) and incubated for $72 \mathrm{~h}$. (evaluation after 24 and $72 \mathrm{~h}$ ) at $37^{\circ} \mathrm{C}$.

The lowest concentrated ungrown (clear) test-tube was noted as minimum inhibitory concentration; from this tube, $0.1 \mathrm{ml}$ was plated on blood agar after the $72 \mathrm{~h}$ of incubation in order to determine preliminarily whether MIC-values corresponded to minimum bactericidal (MBC)-values.

Classification. According to Bischoff et al. (2012), isolates were classified as "non-wildtype" if DDAC had MICs > $1.4 \mathrm{mg} / \mathrm{l}$. This classification was additionally supported by the data of 27 enterococcal isolates from wild Finish grouse, with a range of $0.35-1.4 \mathrm{mg} / \mathrm{l}$ and a median of $0.35 \mathrm{mg} / \mathrm{l}$ (data not shown).

\section{Antibiotic agents}

Antibiotic resistance was determined by microdilution following DIN 58940-81 recommendations as previously described (Hölzel et al., 2010). All 969 enterococci were tested for antibiotic resistance using a panel of 22 agents. Enterobacteriaceae from boot bath disinfectant were tested with 13 and Gram-positives with 20 antibiotics (Table 1).

\section{ADAPTATION TO INCREASING DDAC-CONCENTRATIONS}

Four isolates of E. faecalis (E. faecalis DSM 2570 and 3 field strains with non-wildtype MIC-values for DDAC of $2.7 \mathrm{mg} / \mathrm{l}$ ) were adapted to grow in gradually increasing DDAC concentrations for up to 70 days. Several colonies of the isolates were picked from blood agar plates and were cultured in $10 \mathrm{ml}$ of TS-broth $\left(37^{\circ} \mathrm{C}\right.$ on a shaker at $\left.200 \mathrm{rpm}\right)$. After $24 \mathrm{~h}, 1 \mathrm{ml}$ suspension was transferred into $9 \mathrm{ml}$ of TS-broth supplemented with DDAC $(0.7-21.9 \mathrm{mg} / \mathrm{l}=0.001-0.03 \%$; starting at $\log 2 \mathrm{MIC}-1)$ and incubated as mentioned above for another $24 \mathrm{~h}$. The adaption process was initiated as follows: for each strain, the highest concentrated DDAC suspension which still allowed growth $\left(c_{\max }\right)$ was centrifuged. The resulting pellet was washed thrice with WSH and homogenized. One $\mathrm{ml}$ of this WSH suspension was transferred into TS-broth containing DDAC in the following final concentrations (i) $\log 2 c_{\max }-1$ (ii) $\log 2 c_{\max }$ and (iii) $\log$ $2 c_{\max }+1$ and incubated as mentioned above. Accompanying, one loop-full of the inoculating suspension was streaked onto sheep-blood-agar in order to ensure the purity of cultures. This process was repeated every $24 \mathrm{~h}$.

\section{DNA-EXTRACTION}

DNA was extracted from pure bacterial cultures of E. faecalis, E. faecium, or E. coli using cetyltrimethylammoniumbromide (CTAB) as previously described (Korthals et al., 2008)

\section{RAPD-PCR}

In order to investigate whether DDAC-tolerant strains were clonally related, isolates were amplicon-typed by RAPD-PCR.

\section{E. faecalis}

Amplicons of $E$. faecalis were generated using primer M13R2: GGAAACAGCTATGACCATGA (Martin et al., 2005). PCRconditions were denaturation at $95^{\circ} \mathrm{C}$ for 15:00 (min:sec), followed by 40 cycles of melting at $94^{\circ} \mathrm{C}$ for $00: 30$, annealing at $38^{\circ} \mathrm{C}$, 01:00, elongation at $72^{\circ} \mathrm{C}, 01: 00$ and a final extension step at $72^{\circ} \mathrm{C}$ for 05:00.

\section{E. faecium}

Amplicons of E. faecium were generated using primer D8635: GAGCGGCCAAAGGGA GCAGAC (Akopyanz et al., 1992) with two different PCR conditions (Andrighetto et al., 2001): (i) $95^{\circ} \mathrm{C}$ for 15:00 (min:sec), followed by 35 cycles of melting at $94^{\circ} \mathrm{C}$ for 01:00, annealing at $47^{\circ} \mathrm{C}, 01: 00$, elongation at $72^{\circ} \mathrm{C}, 01: 30$ and a final extension step at $72^{\circ} \mathrm{C}$ for 10:00. (ii) Pre-PCR Cycle with $95^{\circ} \mathrm{C}, 15: 00 ; 40^{\circ} \mathrm{C}, 05: 00 ; 72^{\circ} \mathrm{C}, 05: 00$, followed by 35 cycles of $94^{\circ} \mathrm{C}, 01: 00 ; 52^{\circ} \mathrm{C}, 01: 00 ; 72^{\circ} \mathrm{C}, 02: 00$ and a final extension step at $72^{\circ} \mathrm{C}$ for $10: 00$.

\section{INVESTIGATION OF THE EmEA-GENOTYPE}

All enterococci with DDAC-MICs $>1.4 \mathrm{mg} / \mathrm{l}$ were previously shown to be negative for qac-genes (qac A/B, smr [qacC/qacD], qac $\Delta 1$, qac $\mathrm{G}$, qacJ qacH/qacZ; Bischoff et al., 2012); one of the isolates was a qacA/B-negative variant of a strain which was previously shown to harbor qacA/B (Bischoff et al., 2012). Since emeA, a multidrug efflux pump with sequence homology to the staphylococcal nor A gene, is suspected to contribute to reduced disinfectant susceptibility, 44 E. faecalis-isolates (E. faecalis DSM 2570; eight study strains with MIC less or equal 1.05 and 35 study strains with $\mathrm{MIC}>1.4$ ) were investigated for their emeA-genotype using primers emeA-fw GACTCAACGAGTGTTTCAGCCAA and emeA-rv ACGATAAAAAGCCCGTTCCTA as suggested by NCBI 
Table 1 | Antibiotic agents, concentration ranges, and breakpoints.

\begin{tabular}{|c|c|c|c|c|c|}
\hline Name of antibiotic & Range (mg/l) & \multicolumn{2}{|c|}{ Breakpoint (mg/l) } & Tested against & References \\
\hline Ampicillin & $1 / 2-128 / 20.125 / 2-8 / 2$ & 84 & 88 & Gram-neg.Gram-pos. & EUCAST \\
\hline Cefaclor & $1-8$ & 1 & 4 & Gram-neg. & $\operatorname{DIN}^{1}$ \\
\hline Cefazolin & $0.125-16$ & 4 & 8 & Gram-neg. Gram-pos. & DIN \\
\hline Chloramphenicol & 2-64 & 16 & 16 & Enterococci & DANMAPa \\
\hline Ciprofloxacin & $0.0625-80.25-32$ & 0.51 & 12 & Gram-neg. Gram-pos. & EUCASTDIN \\
\hline Clindamycin & $0.0625-8$ & 1 & 4 & Gram-pos. ${ }^{b}$ & DIN \\
\hline Doxycycline & $0.5-40.125-16$ & 1 & 4 & Gram-neg. Gram-pos. & DIN \\
\hline Enrofloxacin & 0.0625-8 & 0.25 & 2 & Gram-neg. Gram-pos. & CLSI \\
\hline Gentamicin & $0.25-32$ & 21 & 41 & Gram-neg.Gram-pos. & EUCASTEUCASTC \\
\hline Gentamicin $\mathrm{HL}^{d}$ & 512 & 512 & 512 & Enterococci & DANMAP \\
\hline Imipenem & $0.125-16$ & 24 & 88 & Gram-neg.Gram-pos. & EUCAST \\
\hline Linezolid & $0.125-16$ & 4 & 4 & Gram-pos. & EUCAST \\
\hline Meropenem & $0.125-16$ & 2 & 8 & Gram-neg. & EUCAST \\
\hline Mezlocillin & $2-256$ & 4 & 16 & Gram-pos. & DIN \\
\hline Moxifloxacin & $0.0625-8$ & 1 & 2 & Gram-pos. & DIN \\
\hline Rifampicin & $0.5-4$ & 0.006 & 0.5 & Gram-pos. & EUCAST'b \\
\hline Streptomycin $\mathrm{HL}^{\mathrm{d}}$ & $256-2048$ & 512 & 512 & Enterococci & EUCAST \\
\hline Synercid & $0.125-16$ & 1 & 4 & Gram-pos. ${ }^{a}$ & EUCAST \\
\hline Teicoplanin & $0.25-32$ & 2 & 2 & Gram-pos. & EUCAST \\
\hline
\end{tabular}

Primer Blast. PCR-conditions were denaturation at $94^{\circ} \mathrm{C}$, 05:00 (min:sec), followed by 30 cycles of melting at $94^{\circ} \mathrm{C}$, annealing at $63^{\circ} \mathrm{C}, 01: 00$, elongation at $72^{\circ} \mathrm{C}, 01: 00$ and a final extension step at $72^{\circ} \mathrm{C}, 05: 00$.

\section{Melting curve analysis}

Amplicons were investigated by conventional melting curve analysis under the following conditions: step $1: 95^{\circ} \mathrm{C}$, slope $20^{\circ} \mathrm{C} / \mathrm{sec}$; step 2: $65^{\circ} \mathrm{C}$, hold-time 30 s., slope $20^{\circ} \mathrm{C} /$ sec; step 3: $95^{\circ} \mathrm{C}$, slope $0.1^{\circ} \mathrm{C} / \mathrm{sec}$. Delta Tm was recorded as follows: Tm (wildtype) minus $\mathrm{Tm}$ (variant), with $\mathrm{Tm}=$ temperature at the maximum value for $-\mathrm{d}(\mathrm{F} 1) / \mathrm{dT}$ (maximum of the melting peak). Peaks were suspected to be different if Delta Tm was at least $0.6^{\circ} \mathrm{C}$. A diversity of peaks was further investigated by sequence analysis.

\section{Sequence analysis}

DSM-reference strain E. faecalis DSM 2570 (ATCC 29212), for which an emeA-sequence is already recorded in Genbank
(AB091338.1 GI:22775586) and three emeA-amplicons of study isolates were externally sequenced (Sequiserve, Vaterstetten, Germany). Sequences were compared with each other and with nucleotide records - including nine emeA-sequences of $E$. faecalis-in Genbank using the default NCBI-BLAST-program for highly similar sequences.

\section{Relative transcription of emeA-variants}

The transcription of emeA in relation to the transcription of DNA coding for a partial sequence of the 23S-rRNA was investigated by RT-PCR as previously described (Schwaiger et al., 2012), using the emeA-primers as described above and primers GTAGTCCACAGCTTCGGTAATATGT and AACTAGGATGTTGGCTTAG AAGCA for a 23SrDNA-fragment as described elsewhere (Hancock et al., 2003). For a preliminary impression, differences in gene transcription were calculated using the $2^{\wedge}$-DeltaDeltaCt-method. 


\section{STATISTICS}

The prevalence of DDAC-MICs $>1.4 \mathrm{mg} / \mathrm{l}$ within the groups of antibiotic resistant and antibiotic susceptible E. faecalis and $E$. faecium was assessed in a chi-squared test. If expected numbers per cell were below five, a Fisher's Exact test was applied. A nonparametric procedure (Mann-Whitney U) was used to compare the MIC-values of DDAC as well as the MIC-values of antibiotics in strains with different emeA-types.

\section{RESULTS \\ SUSCEPTIBILITY OF E. faecalis AND E. faecium TO DDAC AND ANTIBIOTICS \\ MIC-values for DDAC}

MIC-values for DDAC differed from wildtype-MIC-values only in a small fraction of E. faecalis or E. faecium (Table 2), and only in a very moderate way (Table 3 ). The highest prevalence of DDACMICs $>1.4 \mathrm{mg} / \mathrm{l}$ was seen in enterococci from milk and dairy products $(14.5 \%)$, while the prevalence in livestock was generally low (0-4\%). The maximum multiplication of MIC-values was 3.3-fold ( 1.05 vs. $3.5 \mathrm{mg} / \mathrm{l})$.

All "non-wildtype" MIC-values for DDAC (> $1.4 \mathrm{mg} / \mathrm{l})$ were confirmed in the macrodilution test.

MBC-values did not exceed the MIC-values in any case ( $\mathrm{MBC}=\mathrm{MIC}$ in 44/44 isolates).

\section{Adaptation to increasing DDAC-concentrations}

All isolates which were used in the adaptation test were adapted to grow in higher concentrations (up to $21.9 \mathrm{mg} / \mathrm{l}$ ) during 70 days of adaptation. Despite DDAC-MIC-values of $2.7 \mathrm{mg} / \mathrm{l}$ at the beginning, three human $E$. faecalis strains were not adapted to higher concentrations than the E. faecalis DSM 2570 strain with an initial DDAC-MIC-value of $0.7 \mathrm{mg} / \mathrm{l}$ (Figure 1): at day 5 of the adaptation experiment, DSM 2570 reached the same level as the non-wildtype strains. The DDAC-MIC-value for DSM 2570 increased further on day 6 , while the non-wildtype strains had DDAC-MIC-values of $2.7 \mathrm{mg} / \mathrm{l}$ until day 22; all strains (including the DSM-strain) had DDAC-MICs of $21.9 \mathrm{mg} / \mathrm{l}(4.45 \log 2)$ on day 71 .

\section{MIC-values for antibiotics}

The fraction of DDAC-MICs $<1.4 \mathrm{mg} / \mathrm{l}$ or $>1.4 \mathrm{mg} / \mathrm{l}$ within gentamicin/streptomycin-high-level- and ampicillin-resistant or -susceptible strains of E. faecalis and E. faecium is shown in Table 2. No significant differences were found for $E$. faecalis-neither for these substances, nor for any of the other investigated antibiotics (data not shown). However, for human hospital-derived E. faecium a Fisher's Exact Test revealed that DDAC-MICs $>1.4 \mathrm{mg} / \mathrm{l}$ Enterococcus were significantly $(p<0.05)$ more prevalent in streptomycinhigh-level-resistant isolates: Of the clinical isolates, 1 out of 75 streptomycin-susceptible strains $(1.3 \%)$ vs. 4 out of 22 streptomycin-resistant strains $(18.2 \%)$ were inhibited by DDAC-concentrations $>1.4 \mathrm{mg} / \mathrm{l}$. Significantly elevated prevalences of isolates with DDAC-MICs $>1.4 \mathrm{mg} / \mathrm{l}$ were also seen within clinical gentamicin- and ampicillin-resistant isolates (Table 2).

Table 2 | Prevalence of E. faecalis and E. faecium with DDAC-MICs $>1.4 \mathrm{mg} / \mathrm{l}$ within antimicrobial-susceptible and -resistant isolates of different sources.

\begin{tabular}{|c|c|c|c|c|c|c|c|c|}
\hline \multirow[t]{2}{*}{ Source } & \multicolumn{8}{|c|}{ Prevalence of strains with DDAC-MICs $>1.4 \mathrm{mg} / \mathrm{l}(\mathrm{n})$ within all investigated isolates (N) } \\
\hline & Total & Total\% & $\begin{array}{c}\text { GNH }^{\mathrm{a}} \\
\text { susceptible }\end{array}$ & $\begin{array}{c}\text { GNH } \\
\text { resistant }\end{array}$ & $\begin{array}{c}\text { SNH }^{\mathbf{b}} \\
\text { susceptible }\end{array}$ & $\begin{array}{c}\text { SNH } \\
\text { resistant }\end{array}$ & $\begin{array}{c}\text { AMPc }^{\mathrm{c}} \\
\text { susceptible }\end{array}$ & $\begin{array}{c}\text { AMP } \\
\text { resistant }\end{array}$ \\
\hline \multicolumn{9}{|l|}{ E. faecalis } \\
\hline Hospital: human blood & $6(88)$ & 6.8 & $6(62)$ & $0(26)$ & $5(60)$ & $1(28)$ & $6(85)$ & $0(3)$ \\
\hline Hospital: human feces & $8(210)$ & 3.8 & $7(144)$ & $1(56)$ & $6(177)$ & $2(33)$ & $8(210)$ & $0(0)$ \\
\hline Outpatient feces & $3(102)$ & 2.9 & $3(94)$ & $0(8)$ & $3(96)$ & $0(16)$ & $3(102)$ & $0(0)$ \\
\hline Swine, feces & $0(76)$ & 0.0 & & & & & & \\
\hline Cattle, feces & $0(50)$ & 0.0 & & & & & & \\
\hline Cattle, matistis milk & $0(50)$ & 0.0 & & & & & & \\
\hline Chicken, feces & $2(50)$ & 4.0 & $2(48)$ & $0(2)$ & $2(46)$ & $0(4)$ & $2(50)$ & $0(0)$ \\
\hline Milk and dairy products & $14(96)$ & 14.6 & $13(95)$ & $1 *(1)$ & $14(95)$ & $0(1)$ & $2(96)$ & $0(0)$ \\
\hline Poultry & $2(54)$ & 3.7 & $2(54)$ & $0(0)$ & $2(43)$ & $0(11)$ & $2(54)$ & $0(0)$ \\
\hline Beef & $3(30)$ & 10.0 & $3(30)$ & $0(0)$ & $3(29)$ & $0(1)$ & $3(30)$ & $0(0)$ \\
\hline Pork & $1(28)$ & 3.6 & $1(26)$ & $0(2)$ & $1(25)$ & $0(3)$ & $1(28)$ & $0(0)$ \\
\hline \multicolumn{9}{|l|}{ E. faecium } \\
\hline Hospital: human blood & $3(45)$ & 6.7 & $1(31)$ & $2(14)$ & $1(32)$ & $2(13)$ & $0(7)$ & $3(38)$ \\
\hline Hospital: human feces & $2(52)$ & 3.8 & $0(42)$ & $2 *(10)$ & $0(43)$ & $2^{*}(9)$ & $0(38)$ & $2 *(14)$ \\
\hline Outpatient: feces & $2(38)$ & 5.3 & $2(38)$ & $0(0)$ & $2(36)$ & $0(2)$ & $2(37)$ & $0(1)$ \\
\hline
\end{tabular}

a GNH gentamicin (high level).

${ }^{b}$ SNH streptomycin high level.

${ }^{c}$ AMP ampicillin.

${ }^{*}$ Differs significantly in a Fisher's Exact Test from the overall prevalence in this study, $p<0.05$.

Bold: emphasized for the sake of clarity 
Table 3 | Minimal inhibitory concentrations and antimicrobial resistance of antiseptic-tolerant (MIC > 1.4 mg DDAC/I) Enterococcus isolates.

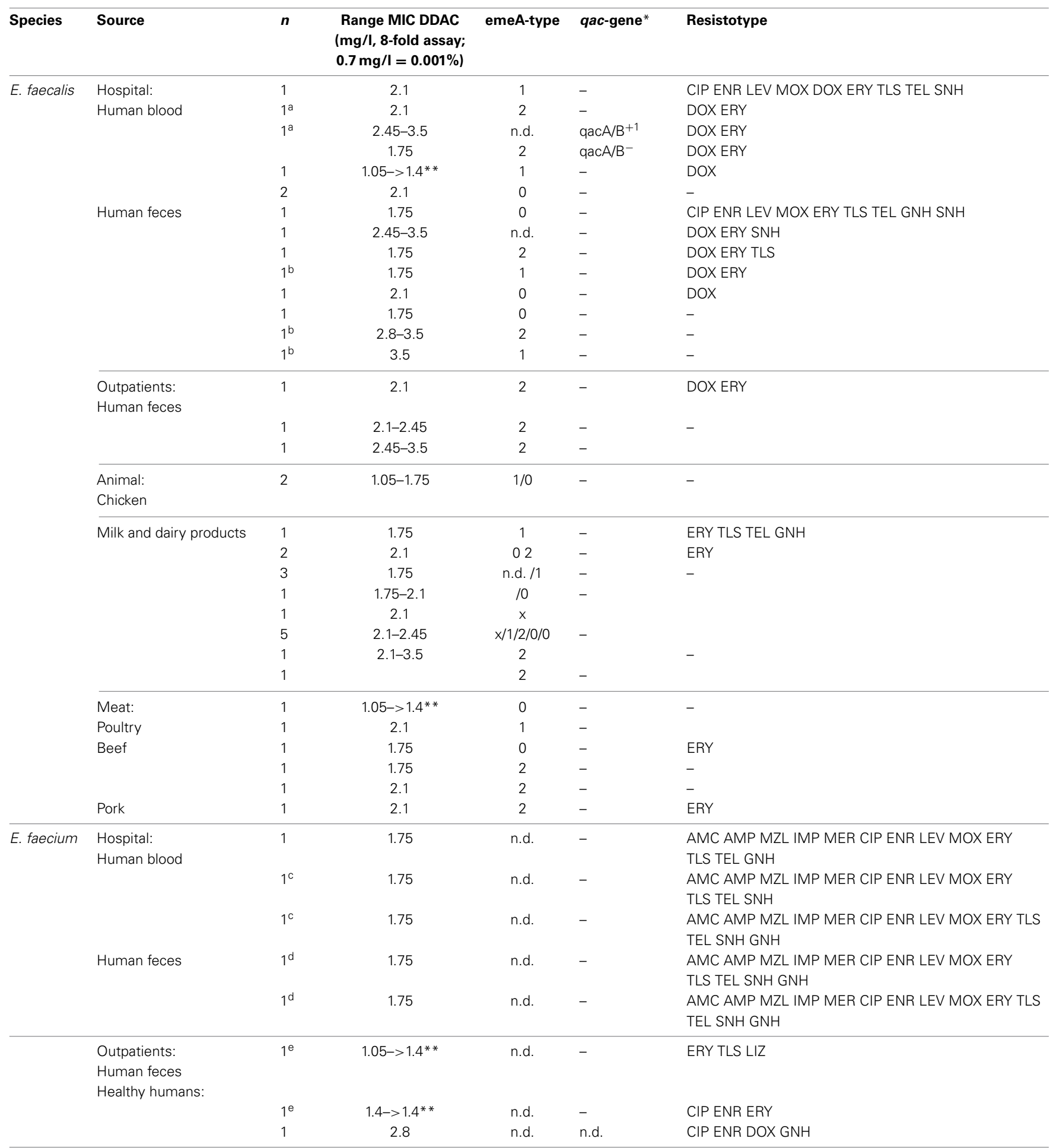

${ }^{1}$ (Bischoff et al., 2012).

a,b,c,d Originating from different patients of the same hospital in the same period of investigation, respectively; ${ }^{e}$ isolates of two different outpatients, sent in from the same laboratory in the same period of investigation.

DDAC, Didecyldimethylammoniumchloride; AMC, Amoxicillin + Clavulanate; AMP, Ampicillin; MZL, Mezlocillin; IMP, Imipenem; MER, Meropenem; CIP, Ciprofloxacin; ENR, Enrofloxacin; LEV, Levofloxacin; MOX, Moxifloxacin; ERY, Erythromycin; TLS, Tylosin; TEL, Telithromycin; GNH, Gentamicin High Level; SNH, Streptomycin High Level; LIZ, Linezolid.

*Investigated qac-genes: qacA/B, qacC, qacD, qacE 1 , qacG, qacH/qacZ, qacJ. ${ }^{* *} D D A C$-tolerance was reproduced twice, but not at the third time. 


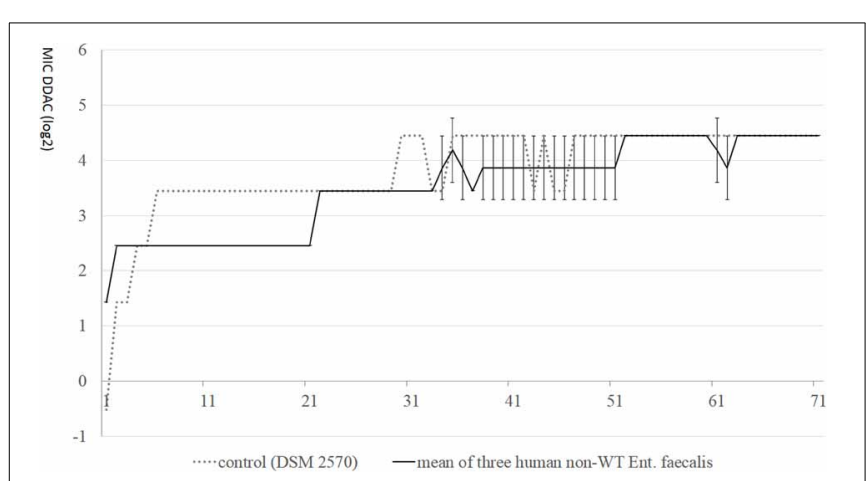

FIGURE 1 | MIC-values (log2) of didecyldimethylammoniumchloride (DDAC) in E. faecalis with initial MICs > $1.4 \mathrm{mg} / \mathrm{l}$, compared with control DSM 2570 during 70 days of stepwise adaptation.

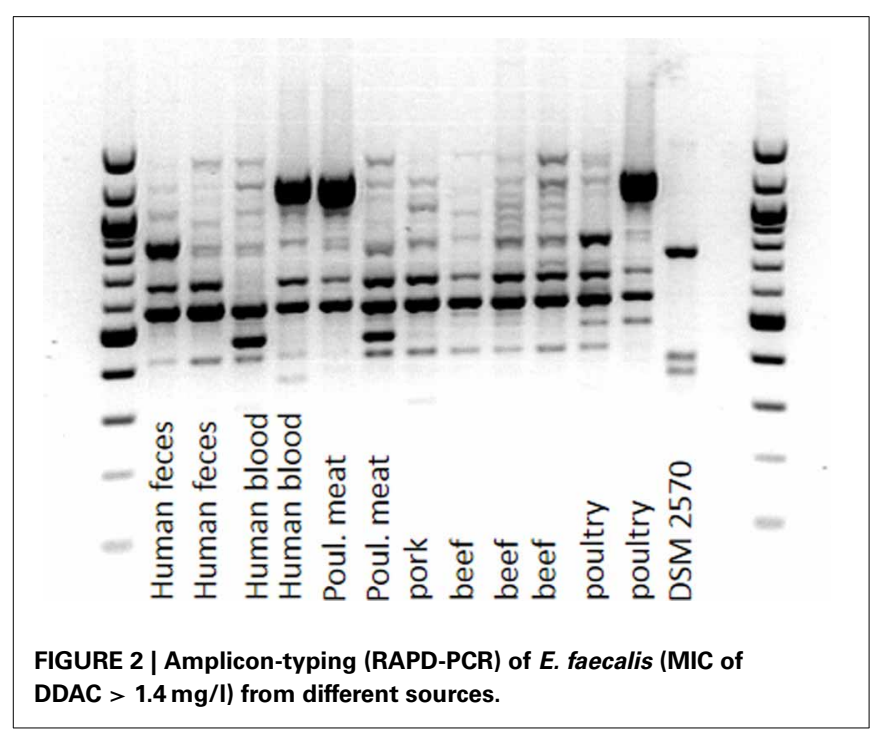

\section{PHYLOGENETIC DIVERSITY OF STRAINS WITH DDAC-MIC $>1.4 \mathrm{mg} / \mathrm{I}$}

In order to reveal whether enterococci with DDAC-MICs > $1.4 \mathrm{mg} / \mathrm{l}$ belonged to one or more clonal lineages, the phylogenetic diversity of the study isolates with DDAC_MIC $>1.4 \mathrm{mg} / \mathrm{l}$ was investigated by RAPD-PCR. The investigated strains of $E$. faecalis belonged to at least three distinct RAPD-types. However, compared to the completely distinct RAPD-profile of the reference strain, profiles of strains with DDAC-MIC $>1.4 \mathrm{mg} / \mathrm{l}$ were more similar, indicating a certain degree of phylogenetic relatedness, but no clonality (an example is given in Figure 2). One identical RAPD-profile was shared by one isolate from human blood, from poultry and from poultry meat, respectively (Figure 2).

The RAPD-profiles of E. faecium with DDAC-MICs $>1.4 \mathrm{mg} / \mathrm{l}$ were similar for the fecal isolates including the (wildtype) DSM type strain, but differed from the bloodstream isolate (Figure 3).

\section{emeA-GENOTYPE IN E. faecalis WITH DDAC-MICS > $1.4 \mathrm{mg} / \mathrm{l}$ Melting curve analysis}

Conventional melting curve analysis of E. faecalis-emeAamplicons resulted in two clearly distinguishable peaks (type 1

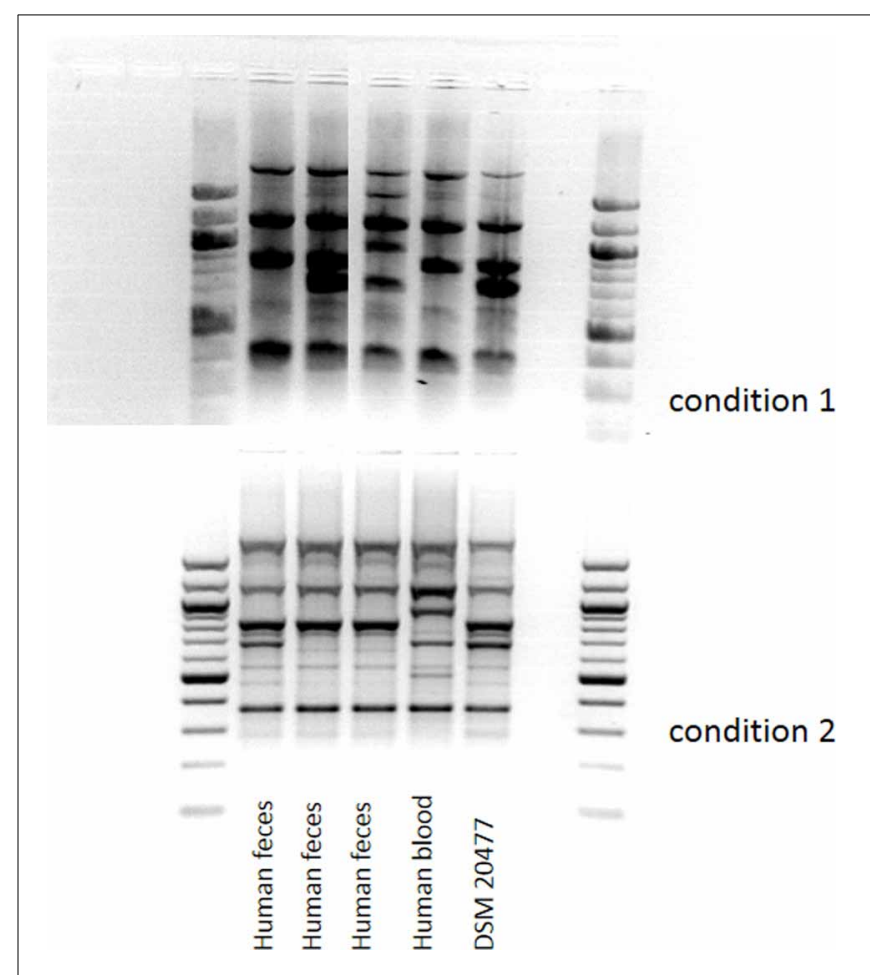

FIGURE 3 | Amplicon-typing (RAPD-PCR, two different conditions) of $E$. faecalis (MIC of DDAC > $1.4 \mathrm{mg} / \mathrm{I}$ ) from different sources.

and 2, Figure 4) at approximately 87 and $86^{\circ} \mathrm{C}$ with Delta $\mathrm{Tm}=$ $\left.0.9 \pm 0.3^{\circ} \mathrm{C}\right)$. Of all investigated isolates, 12 could be clearly attributed to type 1 and 13 could be clearly attributed to type 2 (Table 3). The other isolates had a Delta Tm which could not be unambiguously assigned to one of both types (type 0 ) or had a Tm higher than type 1 (type $\mathrm{x}$ ). E. faecalis DSM 2570 represented the prototype for the higher Tm-value (type 1). This strain and three prototypes for the lower Tm value (type 2) were externally sequenced. Results of a sequence comparison using NCBIPrimer-Blast are given in Table 4. The amplicon of DSM 2570 was completely identical to the corresponding sequence of DSM $2570=$ ATCC 29212 recorded in Genbank by Lee et al. (2003) (Accession AB091338). The amplicons of the three sequenced study-strains differed from this sequence in 9 nucleotides; they matched two other recorded Genbank-sequences: E. faecalis D32 (Accession CP003726) and E. faecalis 62 (Accession CP002491).

All differences between the DSM-strain and the sequenced study strains (as well as D32 and 62) were synonymous substitutions which do not affect the sequence of amino acids.

The median DDAC-MIC-value for investigated isolates with type 1 melting curves was $1.5(1.05-3.5) \mathrm{mg} / \mathrm{l}$, the median MIC for isolates with type 2 melting curves was 2.1 (1.75-3.2) $\mathrm{mg} / \mathrm{l}$, resulting in a significant difference in a non-parametric test (Mann-Whitney U, $p<0.01$ ). Of eight investigated wildtype strains $(\mathrm{MIC}<1.4 \mathrm{mg} / \mathrm{l})$, none was attributed to melting type 2 (Table 3).

The number of phenotypic antibiotic resistances was $0-3$ in isolates with emeA-type 2 and $0-9$ in type 1 isolates. The median 
MIC-values of antibiotics differed only insignificantly between isolates of both melting types (Mann-Whitney $\mathrm{U}, p>0.05$ ).

\section{Relative transcript level for two different emeA-variants}

In relation to the basal transcription of DNA coding for a partial sequence of the $23 \mathrm{~s}$ rRNA, relative transcript levels for emeA-variants of type 2 were on average slightly higher than for emeA-variants of type 1 (mean $2^{\wedge}$-DeltaDeltaCt $=5.78$ ). $2^{\wedge}$-DeltaDeltaCt-values (type 2 vs. type 1 ) ranged from 0.2 to 314.5. The maximum of $2^{\wedge}$-DeltaDeltaCt-values within type 1 was 116.4 , the maximum of $2^{\wedge}$-DeltaDeltaCt-values within type 2 was 13.9 , indicating a higher homogeneity in emeA-transcription within the type-2-group.

\section{ISOLATION OF BACTERIA FROM DISINFECTANT BOOT BATH (ACTIVE INGREDIENT: 1.1\% FORMIC ACID) \\ Bacterial identification}

From boot bath disinfectant (1.1\% formic acid), 42 bacterial strains were isolated and differentiated (Table 5). E. coli $(n=7)$ was only isolated from swabs substituted with inactivation medium. Other Enterobacteriaceae (Providencia rettgerie, Acinetobacter lwoffi, Enterobacter cloacae) were also isolated without this inactivation step. Gram-positive cocci (staphylococci

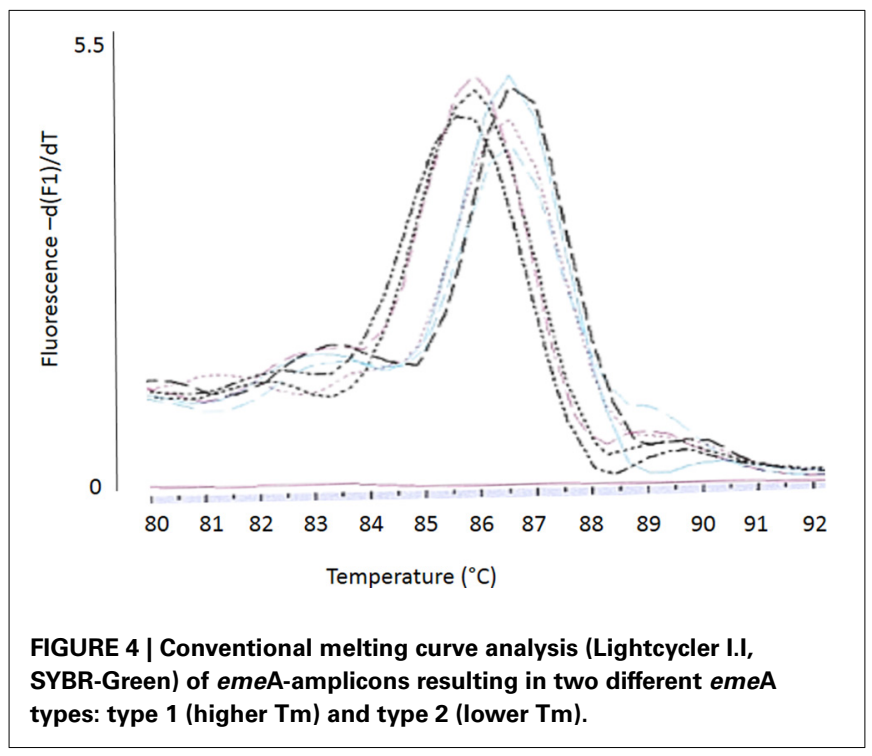

and enterococci) were found in all kinds of sample including the disinfectant solution, although the latter was predominantly positive for Bacillus spp.

\section{MIC-values for formic acid and DDAC}

MIC-values for the formic acid based disinfectant were $0.003-$ $0.14 \%$ and thus below the used concentration of $1.1 \%$ formic acid, indicating that the isolated bacteria were not able to replicate in the disinfectant boot bath. In general, Gram-negative bacteria had higher MIC-values for formic acid (0.03-0.14\%, median $0.14 \%$ ) than Gram-positive bacteria (0.003-0.07\%, median $0.01 \%)$. Besides one isolate, all strains had MIC-values comparable to a DSM reference strain of the same genus; one $S$. saprophyticus strain had a MIC of $0.07 \%$, while S. aureus (DSM 1104 ) and one non-hemolytic S. aureus from the disinfectant fluid had MIC-values of $0.003 \%$ formic acid. MIC-values for DDAC ranged from 1.4 to $21.9 \mathrm{mg} / \mathrm{l}(0.002-0.03 \%$ concentrate, median: $0.008 \%)$ in Gram-negatives, with the highest values seen in $P$. rettgerie and E. cloacae, while $A$. Iwoffii was the most susceptible Gram-negative strain. In Gram-positives, DDAC-MIC-values were $0.7-21.9 \mathrm{mg} / \mathrm{l}(0.001-0.03 \%$ concentrate, median: $0.008 \%)$, with the highest values seen in one of the three $B$. licheniformis isolates. E. faecalis and E. faecium isolates from disinfectant boot bath (active agent: formic acid) had non-wildtype MICs $(0.008 \%$ or $5.6 \mathrm{mg} / \mathrm{l})$ for DDAC.

\section{Natural or acquired resistance to antibiotics}

Of 42 strains isolated from disinfectant boot bath, $9(21.4 \%$, including E. coli) were resistant to amoxicillin + clavulanate, $5(11.9 \%)$ to ciprofloxacin, $6(14.3 \%)$ to doxycycline and 2 $(4.8 \%)$ to tobramycin. P. rettgerie was multiresistant (amoxicillin + clavulanate, doxycycline, tobramycin). Bacillus cereus group isolates were intrinsically resistant to amoxicillin + clavulanate; other Bacillus isolates (B. licheniformis, $n=3$, unidentified Bacillus sp.) were resistant to clindamycin, erythromycin and telithromycin, or to clindamycin only (B. megaterium). No antibiotic resistance was found in B. pumilus and B. subtilis.

\section{DISCUSSION}

Reports on a link of antibiotic resistance and reduced susceptibility to disinfectants are inconsistent: Russell concluded from his review that "bacteria showing reduced susceptibility to biocides may or may not be more resistant to antibiotics"

Table 4 | Polymorphism analysis (NCBI BLAST) of emeA-amplicons as sequenced in the present study.

\begin{tabular}{|c|c|c|c|}
\hline Source & MIC-value (mg/I) & Melting type & Polymorphic nucleotides \\
\hline Child (gastro-intestinal disorder) & 2.7 & 1 & Sequence as above \\
\hline DSMZ (urine) & 1.05 & 2 & 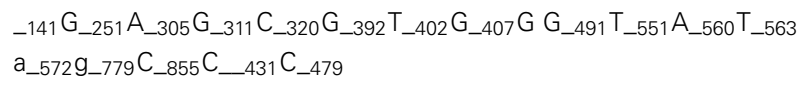 \\
\hline
\end{tabular}

Bold letters: differ from DSM 2570. Other letters: identical with DSM 2570 but variable in other E. faecalis-emeA-entries in the Genbank database. _ spacer for conserved regions in all genbank entries. *Unique variant not seen in any other genbank-entry. 
Table 5 | Antimicrobial resistance and susceptibility to disinfectants of bacteria isolated from boot bath disinfectant $(2 \%$ concentrate $=1.1 \%$ formic acid).

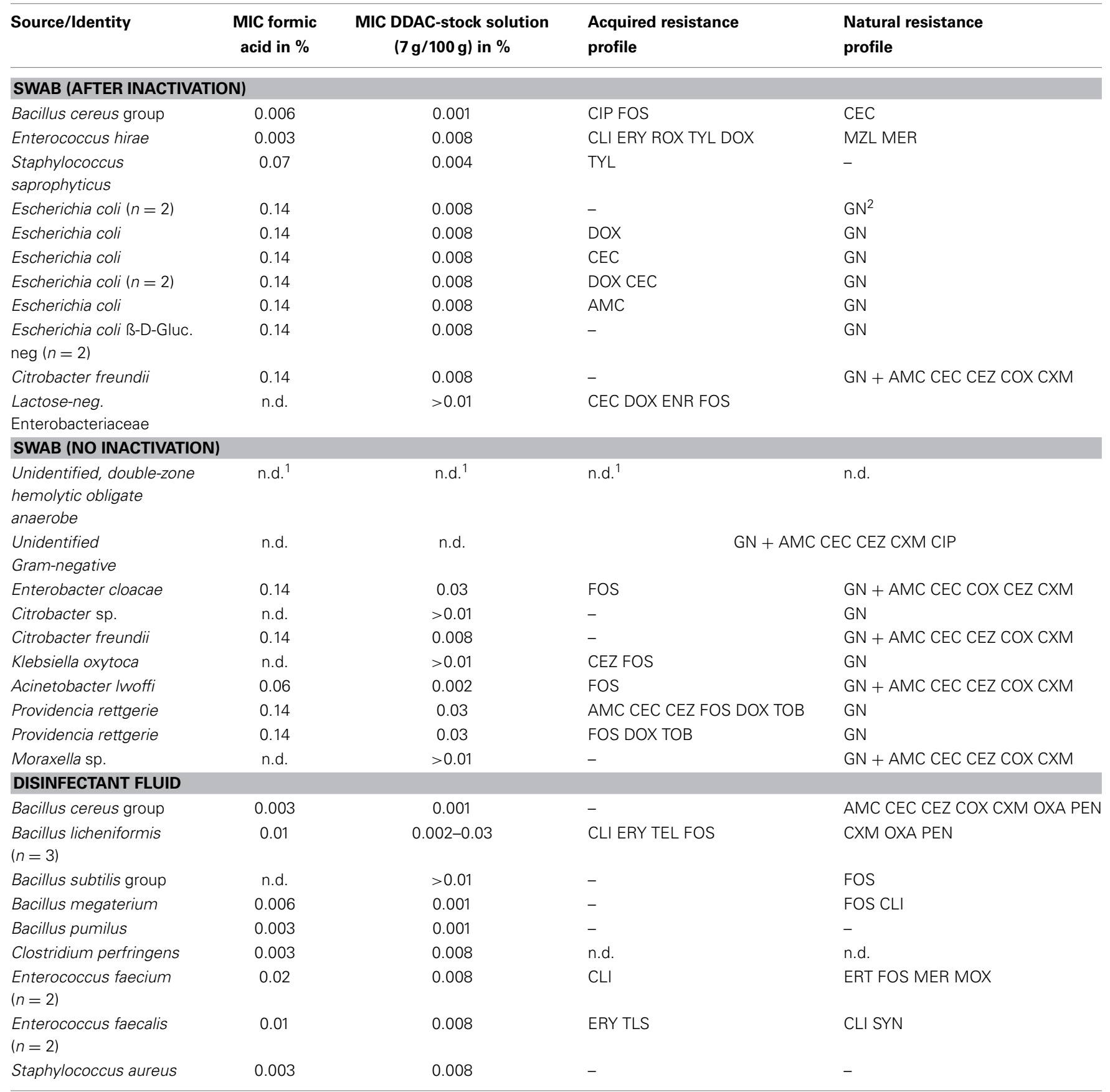

${ }^{1}$ No growth in TS-broth, CAMHB, and Wilkens Chalgren broth in aerobic or anaerobic conditions.

${ }^{2} \mathrm{GN}$ : natural resistance to antibiotics which are ineffective in Gram-negatives like benzylpenicillin, macrolides, lincosamides, streptogramins. DDAC, Didecyldimethylammoniumchloride; AMC, Amoxicillin + clavulanate; AMP, Ampicillin; CEC, Cefaclor; CEZ, Cefazolin; CIP, Ciprofloxacin; COX, Cefoxitin; CXM, Cefuroxime; FOS, Fosfomycin; DOX, Doxycycline; MER, Meropenem; ENR, Enrofloxacin; ERT, Ertapenem; ERY, Erythromycin; LEV, Levofloxacin; MOX, Moxifloxacin; TLS, Tylosin; TEL, Telithromycin.

(Russell, 2002). This might be due to species-specific differences, since many of the studies which report such a link are related to staphylococci (Zmantar et al., 2011). Since enterococci have rarely been representatively investigated up to now, this study aimed to provide completing data. The investigated disinfectant - a quaternary ammonium compound, DDAC-is used in every relevant context (food-producing environment, livestock, clinical settings) and listed by the German Veterinary 
Medical Society (DVG, 2008) as well as the German Association for Hygiene and Microbiology (DGHM), which are the most important reference institutions for recommending disinfectants in Germany. Recommended concentrations of the stock solution in the ready to use fluid range from 0.5 to $4 \%$ (350-2800 mg DDAC/l).

None of the investigated Enterococcus isolates-whether antibiotic resistant or not-was able to grow in a DDAC concentration recommended for in praxi use $(0.5 \%=5 \mathrm{ml}$ stock solution per liter; stock solution $=7 \mathrm{~g} D D A C / 100 \mathrm{~g})$. However, since disinfectants are applied to frequently cleaned environments, rinsing might shape environmental niches with low concentrations of disinfectants. This is especially true in case of improper use (e.g., application to wet surface), but might also happen with proper use, since DDAC is non-volatile and stable to hydrolysis (Juergensen and Busnarda, 2000). Thus, wastewater disposal lines might provide permanent contact between bacteria and low concentrations of disinfectants. The same might be true for biofilm-associated bacteria in production lines like milklines. Relating to this, it might be interesting that the prevalence of DDAC-MICs $>1.4 \mathrm{mg} / \mathrm{l}$ was comparatively high in enterococci from dairy products.

The maximum observed MIC in our field study was 3.5 $(0.005 \%)$, but after 70 days of adaptation in the laboratory, MICs of $21.9 \mathrm{mg} / \mathrm{l}(0.03 \%)$ were observed. Thus, permanent contact to low concentrations of disinfectants might considerably lower the susceptibility for these disinfectants. However, in the present study we could not substantiate that bacteria with higher initial MIC-values are more rapidly adapted to rising concentrations of QACs, as observed by others (Sidhu et al., 2002a,b).

With the macrodilution test followed by plating, we could not find differences between the minimum inhibitory and minimum bactericidal concentration of enterococci. Russell (2003) emphasizes that testing for lethal effects is superior to MIC-testing when assessing the effectiveness of disinfectants. This statement is underlined by the fact that Gram-negative bacteria are regularly reported to have higher MIC-values for disinfectants (Russell, 2001), suggesting lower susceptibility; however, at the same time, they might have lower MBC-values: Walsh et al. (2003) report that equal concentrations of a DDAC did more effectively reduce E. coli (but not Pseudomonas spp.) than S. aureus. Indeed, we could isolate Gram-positive cocci directly from $2 \%$ boot bath disinfectant fluid, while we did not find Gram-negatives in there.

In contrast to the expectation of higher disinfectant-MICvalues in Gram-negatives, in this study we found an identical maximum DDAC-MIC in Gram-positives (one of three B. licheniformis) and Gram-negatives (E. cloacae, P. rettgerie), as well as identical median values; only the minimum DDAC-MIC value was one $\log 2$-step lower in Gram-positives. However, MICs of formic acid were consistently higher in Gram-negatives.

Isolation of bacteria from disinfectant fluid does not necessarily mean that the disinfectant is ineffective, since the in praxi bacterial inoculum (and therefore the log10-reduction, for which several guidelines set the critical limit at greater than or equal to 5, e.g., BS EN 1276) was unknown. As long as bacteria do not reproduce, they are not enriched in the disinfectant fluid. Formic acid inhibited growth (=reproduction) of all bacteria isolated from boot bath disinfectant (1.1\% formic acid) at concentrations $=0.14 \%$ in clean conditions. However, any disinfectant vanishes with time (or rinsing), and the protection of certain bacteria (while others are killed) will indeed affect the bacterial community in a post-disinfection environment (McBain et al., 2004). Thus it should be mentioned that we isolated E. coli with a derepressed AmpC-phenotype from the disinfectant boot bath, as well as multiresistant $P$. rettgerie. However, these isolates were accompanied by susceptible isolates of the same species (and thus ecological niche), and the E. coli were only found after an inactivation step.

Although all formic acid MIC-values were below the used concentration, one S. saprophyticus strain had a MIC-value of $0.07 \%$, which was eye-catching compared to the $S$. aureus isolates with a MIC-value of $0.003 \%$. Thus, high MIC-values might indeed be also indicative for an enhanced ability to survive in disinfectant surroundings (elevated MBC-values), even for structurally unrelated substances. However, vice versa low MIC-values do not exclude high MBC-values (Russell et al., 1999).

The presence of four Enterococcus isolates (two E. faecalis, two E. faecium) with non-wildtype MICs for DDAC is interesting, remembering the very low prevalence of such strains within these two species (e.g., E. faecalis: 0/50 porcine isolates) as seen in the representative DDAC-MIC-screening. The selection of such strains in a chemically completely distinct agent might be indicative that these enterococci use an unspecific way to reduce their susceptibility to chemical agents. Indeed, disinfectant resistance in enterococci has been linked to multidrug efflux pumps before (Poole, 2002). Since we investigated the E. faecalis isolates which showed DDAC-MICs $>1.4 \mathrm{mg} / \mathrm{l}$ in the screening nearly in vain for qac-genes (only four of 586 strains were positive, Bischoff et al., 2012), we had a closer look on the emeA-genotype, and noticed a variability of this emeA-genotype in a conventional melting curve analysis (verified by sequencing). However, strains with DDAC-MICs $>1.4 \mathrm{mg} / \mathrm{l}$ could not be consistently linked to one emeA-type, although the MIC-values of type 2 were statistically significantly higher than the MIC of type 1 and type 2 melting curves were absent in wildtype strains. The only difference between type 2 and the DSM-reference-strain (type 1) were nine synonymous substitutions. Thus, we do not assume that these substitutions affected the activity of the multidrug transporter. However, Berg and Martelius stated that an increase in synonymous substitutions might be caused by differences in gene expression (Berg and Martelius, 1995). Indeed, when we had a first glance at the mean relative transcript-levels of the two different emeAvariants, the relative transcript-levels for type 2 with the higher mean MIC-value was slightly (but insignificantly) higher. Further investigations on the gene expression level would be needed to verify this tendency, and further analysis of the promoter region might elucidate the cause for an enhanced transcription of emeA.

Multidrug efflux transporters of the emeA-type would only partially explain disinfectant-antibiotic "cross-resistance," since they induce no or only minor changes in MIC-values for several antibiotics which were present in the multidrug resistant 
phenotypes of our isolates, like tetracyclines, macrolides or even fluoroquinolones (Lee et al., 2003). Interestingly, the number of phenotypic antibiotic resistances was $0-3$ in isolates with emeAtype 2, but $0-9$ in type 1 isolates, giving reason for ongoing investigations of a transferable nature of DDAC-non-wildtype phenotypes in the multiresistant isolate, due to another mechanism which is not related to emeA.

One multiresistant E. faecalis isolate mentioned above had a resistance profile similar to multiresistant E. faecium isolates (including gentamicin high level resistance and streptomycin high level resistance). For these E. faecium isolates, a statistically significant association of DDAC-MICs $>1.4 \mathrm{mg} / \mathrm{l}$ and gentamicin high level resistance, streptomycin high level resistance, and ampicillin resistance was seen. While E. faecium isolates (MIC DDAC $>1.4 \mathrm{mg} / \mathrm{l}$ ) from the same source (human feces), but different institutions, had similar RAPD-types, the RAPD-type of an $E$. faecium from human bloodstream (MIC DDAC > $1.4 \mathrm{mg} / \mathrm{l}$ ) differed substantially from the others. This indicates that the isolate was not clonally related to the other isolates and thus suggests another reason for congruent resistance phenotypes (like identical multiresistance plasmids). However, we could not prove the transferability of the phenotype or the presence of multiresistance plasmids up to now. It should also be mentioned that the "multiresistant + DDAC-tolerant"-phenotype was only found in few isolates from clinical settings, not in outpatients. However, the only gentamicin high level resistant E. faecium isolate which we found in healthy humans (1/32) also had a DDAC-MIC > $1.4 \mathrm{mg} / \mathrm{l}$ (data not shown).

\section{CONCLUSIONS}

Resistance to in-praxi-concentrations of disinfectants still seems to be rare or even absent in livestock- or food-associated bacteria. This study gives some indication of a link between antibiotic resistance and (moderate) tolerance to disinfectants in a constrained number of isolates. Up to now the main driving force for the spread of such co- or cross-tolerant strains would be the use of antibiotics, not of disinfectants: selective advantage against disinfectants for the biocide-tolerant strains would be restrained to environmental niches (e.g., wastewater disposal lines), due to the fact that the moderately increased disinfectant-MIC-values were still far below disinfectant concentrations used in praxi. Thus, proper use of disinfectants in livestock surroundings still should be highly encouraged, as long as it is accompanied by general good hygiene praxis.

\section{ACKNOWLEDGMENTS}

This study was funded by the Bavarian State Ministry of the Environment and Public Health. Special thanks go to all hospitals and laboratories which provided the human strains with the ethic approval of the Bavarian Federal Medical Association. Thanks go also to Osmo Ratti for providing the samples from Finish grouse. This work was supported by the German Research Foundation (DFG) and the Technische Universität München within the funding programme Open Access Publishing.

\section{REFERENCES}

Aarestrup, F. M., Hasman, H., Jensen, L. B., Moreno, M., Herrero, I. A., Domínguez, L., et al. (2002). Antimicrobial resistance among enterococci from pigs in three European countries. Appl. Environ. Microbiol. 68, 4127-4129. doi: 10.1128/AEM.68.8.4127-4129.2002

Akopyanz, N., Bukanov, N. O., Westblom, T. U., Kresovich, S., and Berg, D. E. (1992). DNA diversity among clinical isolates of Helicobacter pylori detected by PCR-based RAPD fingerprinting. Nucleic Acids Res. 20, 5137-5142. doi: 10.1093/nar/20.19.5137

Andrighetto, C., Knijff, E., Lombardi, A., Torriani, S., Vancanneyt, M., Kersters, K., et al. (2001). Phenotypic and genetic diversity of enterococci isolated from Italian cheeses. J. Dairy Res. 68, 303-316. doi: 10.1017/S0022029901004800

Baker-Austin, C., Wright, M. S., Stepanauskas, R., and McArthur, J. V. (2006). Coselection of antibiotic and metal resistance. Trends Microbiol. 14, 176-182. doi: 10.1016/j.tim.2006.02.006

Berg, J., Tom-Petersen, A., and Nybroe, O. (2005). Copper amendment of agricultural soil selects for bacterial antibiotic resistance in the field. Lett. Appl. Microbiol. 40, 146-151. doi: 10.1111/j.1472-765X.2004.01650.x

Berg, O. G., and Martelius, M. (1995). Synonymous substitution-rate constants in Escherichia coli and Salmonella typhimurium and their relationship to gene expression and selection pressure. J. Mol. Evol. 41, 449-456. doi: 10.1007/BF00160316

Bischoff, M., Bauer, J., Preikschat, P., Schwaiger, K., Mölle, G., and Hölzel, C. (2012). First detection of the antiseptic resistance gene qacA/B in Enterococcus faecalis. Microb. Drug Resist. 18, 7-12. doi: 10.1089/mdr.2011.0092

Bjorland, J., Steinum, T., Kvitle, B., Waage, S., Sunde, M., and Heir, E. (2005). Widespread distribution of disinfectant resistance genes among staphylococci of bovine and caprine origin in Norway. J. Clin. Microbiol. 43, 4363-4368. doi: 10.1128/JCM.43.9.4363-4368.2005

Bjorland, J., Sunde, M., and Waage, S. (2001). Plasmid-borne smr gene causes resistance to quaternary ammonium compounds in bovine Staphylococcus aureus. J. Clin. Microbiol. 39, 3999-4004. doi: 10.1128/JCM.39.11.3999-4004.2001

Bordas, A. C., Brady, M. S., Siewierski, M., and Katz, S. E. (1997). In vitro enhancement of antibiotic resistance development-interaction of residue levels of pesticides and antibiotics. J. Food Prot. 5, 531-536.

Bronzwaer, S. L. A. M., Cars, O., Buchholz, U., Mölstad, S., Goettsch, W., Veldhuijzen, I. K., et al. (2002). A European study on the relationship between antimicrobial use and antimicrobial resistance. Emerg. Infect. Dis. 8, 278-282. doi: 10.3201/eid0803.010192

Cervinkova, D., Babak, V., Marosevic, D., Kubikova, I., and Jaglic, Z. (2012). The role of the qacA gene in mediating resistance to quaternary ammonium compounds. Microb. Drug Resist. 19, 160-167. doi: 10.1089/mdr.2012.0154

Cozad, A., and Jones, R. D. (2003). Disinfection and the prevention of infectious disease. Am. J. Infect. Control 31, 243-254. doi: 10.1067/mic.2003.49

DVG [German Veterinary Medical Society] e.V. (2008). Guidelines for Evaluating Chemical Disinfectants, part V. Gießen: Verlag der deutschen Veterinärmedizinischen Gesellschaft e.V.

Hancock, L. E., Shepard, B. D., and Gilmore, M. S. (2003). Molecular analysis of the Enterococcus faecalis serotype 2 polysaccharide determinant. J. Bacteriol. 185, 4393-4401. doi: 10.1128/JB.185.15.4393-4401.2003

Heir, E., Sundheim, G., and Holck, A. L. (1999). Identification and characterization of quaternary ammonium compound resistant staphylococci from the food industry. Int. J. Food Microbiol. 48, 211-219. doi: 10.1016/S01681605(99)00044-6

Hölzel, T. S., Harms, K. S., Küchenhoff, H., Kunz, A., Müller, C., Meyer, K., et al. (2010). Phenotypic and genotypic bacterial antimicrobial resistance in liquid pig manure is variously associated with contents of tetracyclines and sulfonamides. J. Appl. Microbiol. 108, 1642-1656. doi: 10.1111/j.13652672.2009.04570.x

Hölzel, T. S., Müller, C., Harms, K. S., Mikolajewski, S., Schäfer, S., Schwaiger, K., et al. (2012). Heavy metals in liquid pig manure in light of bacterial antimicrobial resistance. Environ. Res. 113, 21-27. doi: 10.1016/j.envres.2012.01.002

Jonas, B. M., Murray, B. E., and Weinstock, G. M. (2001). Characterization of emeA, a NorA homolog and multidrug resistance efflux pump, in Enterococcus faecalis. Antimicrob. Agents Chemother. 45, 3574-3579. doi: 10.1128/AAC.45.12.35743579.2001

Juergensen, L., and Busnarda, J. (2000). Fate, behavior, and aquatic toxicity of the fungicide DDAC in the Canadian environment. Environ. Toxicol. 15, 174-200. doi: 10.1002/1522-7278(2000)15:3<174::AID-TOX4>3.0.CO;2-P

Kaatz, G. W., Seo, S. M., and Ruble, C. A. (1993). Efflux-mediated fluoroquinolone resistance in Staphylococcus aureus. Antimicrob. Agents Chemother. 37, 1086-1094. doi: 10.1128/AAC.37.5.1086 
Korthals, M., Ege, M. J., Tebbe, C. C., von Mutius, E., and Bauer, J. (2008). Application of PCR-SSCP for molecular epidemiological studies on the exposure of farm children to bacteria in environmental dust. J. Microbiol. Methods 73, 49-56. doi: 10.1016/j.mimet.2008.01.010

Leavis, H. L., Bonten, M. J. M., and Willems, R. J. L. (2006). Identification of highrisk enterococcal clonal complexes: global dispersion and antibiotic resistance. Curr. Opin. Microbiol. 9, 454-460. doi: 10.1016/j.mib.2006.07.001

Lee, E., Chen, J., Huda, M. N., Kuroda, T., Mizushima, T., and Tsuchiya, T. (2003). Functional cloning and expression of emeA, and characterization of EmeA, a multidrug efflux pump from Enterococcus faecalis. Biol. Pharm. Bull. 26, 266-270. doi: 10.1248/bpb.26.266

Levy, S. B. (2000). Antibiotic and antiseptic resistance: impact on public health. Pediatr. Infect. Dis. J. 19, S120-S122. doi: 10.1097/00006454-20001000100008

Lipsitch, M., and Samore, M. H. (2002). Antimicrobial use and antimicrobial resistance: a population perspective. Emerg. Infect. Dis. 8, 347-354. doi: 10.3201/eid0804.010312

Livermore, D. M. (2005). Minimising antibiotic resistance. Lancet Infect. Dis. 5, 450-459. doi: 10.1016/S1473-3099(05)70166-3

Loughlin, M. F., Jones, M. V., and Lambert, P. A. (2002). Pseudomonas aeruginosa cells adapted to benzalkonium chloride show resistance to other membraneactive agents but not to clinically relevant antibiotics. J. Antimicrob. Chemother. 49, 631-639. doi: 10.1093/jac/49.4.631

Martin, B., Garriga, M., Hugas, M., and Aymerich, T. (2005). Genetic diversity and safety aspects of enterococci from slightly fermented sausages. J. Appl. Microbiol. 98, 1177-1190. doi: 10.1111/j.1365-2672.2005.02555.x

McBain, A. J., Ledder, R. G., Moore, L. E., Catrenich, C. E., and Gilbert, P. (2004). Effects of quaternary-ammonium-based formulations on bacterial community dynamics and antimicrobial susceptibility. Appl. Environ. Microbiol. 70, 3449-3456. doi: 10.1128/AEM.70.6.3449-3456.2004

Nallapareddy, S. R., Wenxiang, H., Weinstock, G. M., and Murray, B. E. (2005). Molecular characterization of a widespread, pathogenic, and antibiotic resistance-receptive Enterococcus faecalis lineage and dissemination of its putative pathogenicity island. J. Bacteriol. 187, 5709-5718. doi: 10.1128/JB.187.16.5709-5718.2005

Ng, E. Y., Trucksis, M., and Hooper, D. C. (1994). Quinolone resistance mediated by norA: physiologic characterization and relationship to flqB, a quinolone resistance locus on the Staphylococcus aureus chromosome. Antimicrob. Agents Chemother. 38, 1345-1355. doi: 10.1128/AAC.38.6.1345

Oliveira, D. C., Tomasz, A., and de Lencastre, H. (2002). Secrets of success of a human pathogen: molecular evolution of pandemic clones of meticillin-resistant Staphylococcus aureus. Lancet Infect. Dis. 2, 180-189. doi: 10.1016/S1473-3099(02)00227-X

Palmer, K. L., and Gilmore, M. S. (2010). Multidrug-resistant enterococci lack CRISPR-cas. MBio 1:e00227-10. doi: 10.1128/mBio.00227-10

Poole, K. (2002). Mechanisms of bacterial biocide and antibiotic resistance. Symp. Ser. Soc. Appl. Microbiol. 31, 55S-64S. doi: 10.1046/j.1365-2672.92. 5s1.8.x

Russell, A. D. (2000). Do biocides select for antibiotic resistance? J. Pharm. Pharmacol. 52, 227-233. doi: 10.1211/0022357001773742

Russell, A. D. (2001). Mechanisms of bacterial insusceptibility to biocides. Am. J. Infect. Control 29, 259-261. doi: 10.1067/mic.2001.115671

Russell, A. D. (2002). Introduction of biocides into clinical practice and the impact on antibiotic-resistant bacteria. J. Appl. Microbiol. 92, 121S-135S. doi: 10.1046/j.1365-2672.92.5s1.12.x

Russell, A. D. (2003). Biocide use and antibiotic resistance: the relevance of laboratory findings to clinical and environmental situations. Lancet Infect. Dis. 3, 794-803. doi: 10.1016/S1473-3099(03)00833-8
Russell, A. D., Suller, M. T., and Maillard, J. Y. (1999). Do antiseptics and disinfectants select for antibiotic resistance? J. Med. Microbiol. 48, 613-615. doi: 10.1099/00222615-48-7-613

Schwaiger, K., Bauer, J., Hörmansdorfer, S., Mölle, G., Preikschat, P., Kämpf, P., et al. (2012). Presence of the resistance genes vanC1 and pbp5 in phenotypically vancomycin and ampicillin susceptible Enterococcus faecalis. Microb. Drug Resist. 18, 434-439. doi: 10.1089/mdr.2011.0227

Schwaiger, K., Hölzel, C., and Bauer, J. (2011). Detection of the macrolide-efflux protein A gene mef(A) in Enterococcus faecalis. Microb. Drug Resist. 17, 429-432. doi: $10.1089 / \mathrm{mdr} .2010 .0192$

Shah, P. M. (2005). The need for new therapeutic agents: what is in the pipeline? Clin. Microbiol. Infect. 11, 36-42. doi: 10.1111/j.1469-0691.2005.01141.x

Sidhu, M. S., Heir, E., Leegaard, T., Wiger, K., and Holck, A. (2002a). Frequency of disinfectant resistance genes and genetic linkage with beta-lactamase transposon Tn552 among clinical staphylococci. Antimicrob. Agents Chemother. 46, 2797-2803. doi: 10.1128/AAC.46.9.2797-2803.2002

Sidhu, M. S., Sørum, H., and Holck, A. (2002b). Resistance to quaternary ammonium compounds in food-related bacteria. Microb. Drug Resist. 8, 393-399. doi: $10.1089 / 10766290260469679$

Suller, M. T., and Russell, A. D. (2000). Triclosan and antibiotic resistance in Staphylococcus aureus. J. Antimicrob. Chemother. 46, 11-18. doi: 10.1093/jac/ 46.1.11

Tailor, S. A., Bailey, E. M., and Rybak, M. J. (1993). Enterococcus, an emerging pathogen. Ann. Pharmacother. 27, 1231-1242.

Walsh, S. E., Maillard, J., Russell, A. D., Catrenich, C. E., Charbonneau, D. L., and Bartolo, R. G. (2003). Activity and mechanisms of action of selected biocidal agents on Gram-positive and -negative bacteria. J. Appl. Microbiol. 94, 240-247. doi: 10.1046/j.1365-2672.2003.01825.x

Willems, R. J. L., Hanage, W. P., Bessen, D. E., and Feil, E. J. (2011). Population biology of Gram-positive pathogens: high-risk clones for dissemination of antibiotic resistance. FEMS Microbiol. Rev. 35, 872-900. doi: 10.1111/j.15746976.2011.00284.x

Willems, R. J., and van Schaik, W. (2009). Transition of Enterococcus faecium from commensal organism to nosocomial pathogen. Future Microbiol. 4, 1125-1135. doi: $10.2217 /$ fmb.09.82

Zmantar, T., Kouidhi, B., Miladi, H., and Bakhrouf, A. (2011). Detection of macrolide and disinfectant resistance genes in clinical Staphylococcus aureus and coagulase-negative staphylococci. BMC Res. Notes 4:453. doi: 10.1186/17560500-4-453

Conflict of Interest Statement: The authors declare that the research was conducted in the absence of any commercial or financial relationships that could be construed as a potential conflict of interest.

Received: 25 June 2013; accepted: 18 February 2014; published online: 18 March 2014. Citation: Schwaiger K, Harms KS, Bischoff M, Preikschat P, Mölle G, Bauer-Unkauf I, Lindorfer S, Thalhammer S, Bauer J and Hölzel CS (2014) Insusceptibility to disinfectants in bacteria from animals, food and humans - is there a link to antimicrobial resistance? Front. Microbiol. 5:88. doi: 10.3389/fmicb.2014.00088

This article was submitted to Antimicrobials, Resistance and Chemotherapy, a section of the journal Frontiers in Microbiology.

Copyright (c) 2014 Schwaiger, Harms, Bischoff, Preikschat, Mölle, Bauer-Unkauf, Lindorfer, Thalhammer, Bauer and Hölzel. This is an open-access article distributed under the terms of the Creative Commons Attribution License (CC BY). The use, distribution or reproduction in other forums is permitted, provided the original author(s) or licensor are credited and that the original publication in this journal is cited, in accordance with accepted academic practice. No use, distribution or reproduction is permitted which does not comply with these terms. 